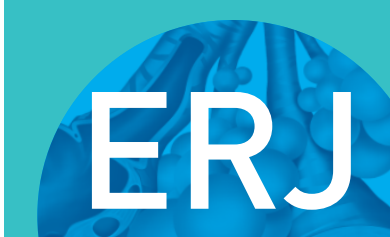

open research

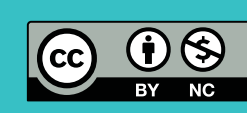

\title{
Should spirometer quality control be treated like other laboratory devices?
}

To the Editor:

Spirometry plays an important role in the diagnosis and management of obstructive and restrictive lung disease [1-4]. To help ensure the accuracy of spirometry testing the American Thoracic Society (ATS)/ European Respiratory Society (ERS) recommend that the calibration of spirometers be verified daily with a 3 - $\mathrm{L}$ syringe and the recorded value should be $3 \mathrm{~L} \pm 3.5 \%$ [5]. This recommendation is based on expert opinion, not evidence. The following case describes a situation where a significant spirometer malfunction was not detected by the ATS/ERS spirometer calibration limits and offers an alternative approach to spirometer quality control.

Calibration verification of a pressure differential pneumotach with a $3-\mathrm{L}$ calibration syringe produced a value of $3.07 \mathrm{~L}$. This reading falls within the ATS/ERS range of acceptability $(2.90-3.10 \mathrm{~L})$, but is historically an unusual reading for this device. Closer inspection of the pneumotach performance including repeat calibration verification, which included pauses between strokes, revealed a positive zero-flow error [6]. A positive zero-flow error can falsely elevate spirometry indices and preclude the achievement of end-of-test criteria [5, 6].

Following this incident, spirometer calibration data from the preceding 6 weeks was used to create a Levey-Jennings chart displaying the mean $\pm 2 \mathrm{sD}$ calibration value (figure 1). Plotting the $3.07 \mathrm{~L}$ calibration value showed that the reading was nearly $6 \mathrm{SD}$ away from the mean value for this device, while still satisfying the ATS/ERS quality control standard. Using the mean $\pm 2 \mathrm{SD}$ as a quality control range is common in laboratory medicine, but not in pulmonary function laboratories. A value outside of these limits is an unusual finding for a properly functioning analyser and should prompt close inspection and troubleshooting of the device. Indeed, in this case using the mean $\pm 2 \mathrm{SD}$ was sensitive to a significant positive zero-flow error where the ATS/ERS recommended range was not. We believe that the performance of modern spirometers allows for tighter calibration ranges [7], including the use of mean $\pm 2 \mathrm{sD}$. For example, one approach would be stipulating that the mean calibration value should be $3 \mathrm{~L} \pm 1.5 \%$ $(2.95-3.05 \mathrm{~L})$ for accuracy and the $2 \mathrm{SD}$ range should not produce a coefficient of variation $>3 \%$ for precision. Spirometer calibration limits could be established by the manufacturer and integrated into the software for each model such that continuous statistics for every calibration are recorded. Alternatively, the software could determine calibration limits for each individual device after clinical testing has begun. Measurements used to calculate the mean and SD of spirometer performance should be carried out on different days. If the pneumotach uses single patient use flow sensors, a different sensor should be used for each calibration. If the precision of a device is too narrow to use SD ranges, a fixed error tighter than the current 3.5\% should be used. Calibration limits based on performance rather than fixed arbitrary values may provide better quality control of spirometer devices.

\section{Jeffrey M. Haynes ${ }^{1}$ and Gregg L. Ruppel $\odot^{2}$}

${ }^{1}$ Pulmonary Function Laboratory, St Joseph Hospital, Nashua, NH, USA. ${ }^{2}$ Division of Pulmonary, Critical Care, and Sleep Medicine, St Louis University, St Louis, MO, USA.

Correspondence: Jeffrey M. Haynes, Pulmonary Function Laboratory, St. Joseph Hospital, 172 Kinsley St, Nashua, NH 03060, USA. E-mail: jhaynes3@comcast.net

@ERSpublications

The ATS/ERS spirometer calibration standards may not be adequate http://ow.ly/Pqdq30nwAmb

Cite this article as: Haynes JM, Ruppel GL. Should spirometer quality control be treated like other laboratory devices? ERJ Open Res 2019; 5: 00249-2018 [https://doi.org/10.1183/23120541.002492018].

Copyright $\odot$ ERS 2019. This article is open access and distributed under the terms of the Creative Commons Attribution Non-Commercial Licence 4.0. 


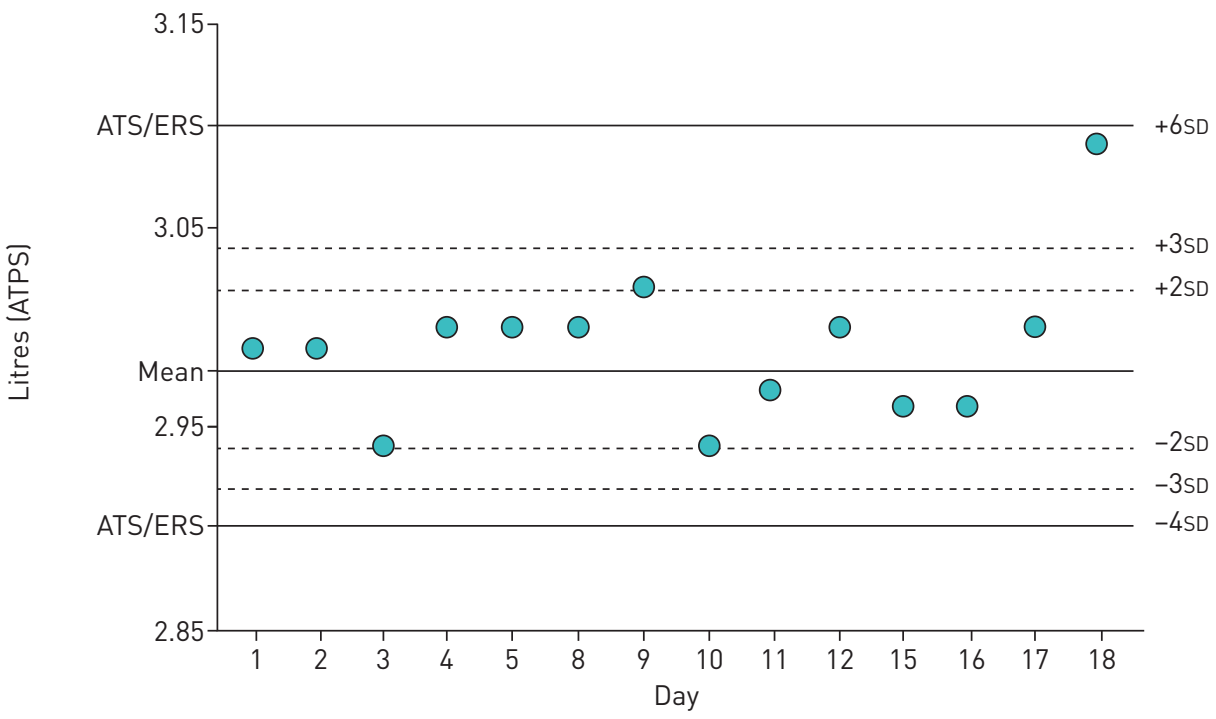

FIGURE 1 Spirometer calibration data plotted as a Levey-Jennings graph. The final datapoint was the product of a positive zero-flow error. Mean \pm SD value: $2.98 \pm 0.02 \mathrm{~L}$. ATPS: ambient temperature and pressure saturated with water vapour; ATS/ERS: American Thoracic Society/European Respiratory Society calibration limits.

Received: Dec 182018 | Accepted: Dec 212018

Conflict of interest: J.M. Haynes reports personal fees from Morgan Scientific Inc. (paid Consultant), outside the submitted work. G.L. Ruppel has no other disclosures except for speaking fees from MGC Diagnostics, outside the submitted work.

\section{References}

1 Pellegrino R, Viegi G, Brusasco V, et al. Interpretative strategies for lung function tests. Eur Respir J 2005; 26: 948-968.

2 Global Initiative for Asthma. Global strategy for asthma management and prevention, 2018. www.ginasthma.org

3 Global Initiative for Chronic Obstructive Lung Disease. Global strategy for the diagnosis, management, and prevention of chronic obstructive pulmonary disease, 2018 report. www.goldcopd.org

4 Raghu G, Collard HR, Egan JJ, et al. An official ATS/ERS/JRS/ALAT statement: idiopathic pulmonary fibrosis: evidence-based guidelines for diagnosis and management. Am J Respir Crit Care Med 2011; 183: 788-824.

5 Miller MR, Hankinson J, Brusasco V, et al. Standardisation of spirometry. Eur Respir J 2005; 26: 319-338.

6 Townsend MC, Hankinson JL, Lindesmith LA, et al. Is my lung function really that good? Flow-type spirometer problems that elevate test results. Chest 2004; 125: 1902-1909.

7 Lefebvre Q, Vandergoten T, Derom E, et al. Testing spirometers: are the standard curves of the American Thoracic Society sufficient? Respir Care 2014; 59: 1895-1904. 